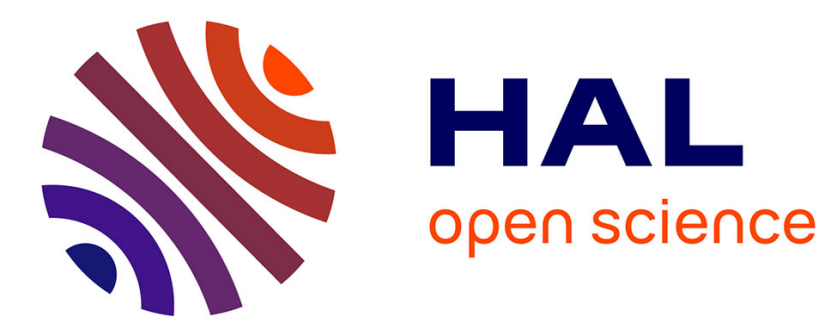

\title{
Controlling starting-point bias in double-bounded contingent valuation surveys
}

Emmanuel Flachaire, Guillaume Hollard

\section{To cite this version:}

Emmanuel Flachaire, Guillaume Hollard. Controlling starting-point bias in double-bounded contingent valuation surveys. Land Economics, 2006, 82 (1), pp.103-111. 10.3368/le.82.1.103 . halshs00175917

\section{HAL Id: halshs-00175917 https://shs.hal.science/halshs-00175917}

Submitted on 1 Oct 2007

HAL is a multi-disciplinary open access archive for the deposit and dissemination of scientific research documents, whether they are published or not. The documents may come from teaching and research institutions in France or abroad, or from public or private research centers.
L'archive ouverte pluridisciplinaire $\mathbf{H A L}$, est destinée au dépôt et à la diffusion de documents scientifiques de niveau recherche, publiés ou non, émanant des établissements d'enseignement et de recherche français ou étrangers, des laboratoires publics ou privés. 


\title{
Controlling starting-point bias in double-bounded contingent valuation surveys
}

\author{
by \\ Emmanuel Flachaire \\ Eurequa, Université Paris 1 Panthéon-Sorbonne \\ and \\ Guillaume Hollard \\ OEP, Université de Marne la Vallée
}

May 2005

\begin{abstract}
In this paper, we study starting point bias in double-bounded contingent valuation surveys. This phenomenon arises in applications that use multiple valuation questions. Indeed, response to follow-up valuation questions may be influenced by the bid proposed in the initial valuation question. Previous researches have been conducted in order to control for such an effect. However, they find that efficiency gains are lost when we control for undesirable response effects, relative to a single dichotomous choice question. Contrary to these results, we propose a way to control for starting point bias in double-bounded questions with gains in efficiency.
\end{abstract}

Keywords: starting point bias, contingent valuation

JEL Classification: Q26, C81

The authors thank Jason Shogren, Stéphane Luchini, Ed Hopkins and two anonymous referees for helpful comments. 


\section{Introduction}

There exist several ways to elicit individuals' willingness to pay for a given object or policy. Contingent valuation, or CV, is a survey-based method to measure nonmarket values, among the important literature see Mitchell and Carson (1989), Hausman (1993), Bateman and Willis (1999). To elicit the individual maximum willingness to pay, participants are given a scenario that describes a policy to be implemented. They are then asked to report the amount they are ready to pay for it.

In order to elicit WTPs, the use of discrete choice format in contingent valuation surveys is strongly recommended by the work of the NOAA panel (Arrow et al. 1993). It consists of asking a bid to the respondent with a question like if it costs $\$ x$ to obtain ...., would you be willing to pay that amount? Indeed, one advantage of the discrete choice format is that it mimics the decision making task that individuals face in everyday life since the respondent accepts or refuses the bid proposed. However, one drawback of this format is that it leads to a qualitative dependent variable (the respondent answers yes or no) which reveals little about individuals' WTP.

In order to gather more information on respondents' WTP, Hanemann (1985) and Carson (1985) proposed to add a follow-up discrete choice question to improve efficiency of discrete choice questionnaires. This mechanism is known as the double-bounded model. This basically consists of asking a second bid to the respondent, greater than the first bid if the respondent answers yes to the first bid and lower otherwise. A key disadvantage of the double-bounded model is that subject's responses to the second bid may be influenced by the first bid proposed. This is the so called starting-point bias.

Several studies document that iterative question formats produce anomalies in respondent behavior. Empirical results show that inconsistent results may appear, that is, the mean WTP may differ significantly if it is implied by the first question only or by the follow-up question. Different interpretations have been proposed - the first bid can be interpreted as an anchor, a reference point ${ }^{1}$ or as providing information about the cost - as well as different models to control for these anomalies (see Cameron and Quiggin 1994, Herriges and Shogren 1996, Alberini, Kanninen, and Carson 1997, Whitehead 2002, DeShazo 2002). However, these studies suggest that when we control for such undesirable response effects, efficiency gains can be lost relative to a single dichotomous choice question.

At the moment, it is still difficult to control for such effects in an effective manner. The purpose of this paper is to address this issue. We present and compare different models previously proposed in the literature. We also develop new econometric models that combine the main feature of existing models. Our empirical results provide strong evidence that we can obtain a gain in efficiency by taking into account the follow-up question. They give a better understanding of how subjects form their responses to the payment questions.

\footnotetext{
${ }^{1}$ Kahneman (1992) proposes clear definitions of anchoring and framing effects and emphasizes the difference in the underlying mental processes.
} 
The paper is organized as follows. In section 2, we review the econometric models proposed in the literature and we propose new models. In section 3, we compare these different models with an application. Conclusions are drawn in section 4.

\section{Econometric models}

In this section, we review different models proposed in the literature to control for the anchoring effect, shift effect and framing effect. Then, we propose new models that combine all these effects.

Let us first consider $W_{0 i}$, the true willingness to pay of individual $i$, which is defined as follows

$$
W_{0 i}=x_{i}(\beta)+u_{i} \quad u_{i} \sim N\left(0, \sigma^{2}\right)
$$

where the unknown parameters $\beta$ and $\sigma^{2}$ are respectively a $k \times 1$ vector and a scalar, where $x_{i}$ is a non-linear function depending on $k$ independent explanatory variables. The number of observations is equal to $n$ and the error terms $u_{i}$ are normally distributed with mean zero and variance $\sigma^{2}$. The willingness to pay (WTP) of the respondent $i$ is not observed but his answer to a bid $b_{i}$ is. The subject's answers are defined as

$$
r_{i}=1 \quad \text { if } \quad W_{0 i}>b_{i} \quad \text { and } \quad r_{i}=0 \quad \text { if } \quad W_{0 i} \leq b_{i}
$$

where $r_{i}=1$ if the respondent $i$ answers yes to the first question and $r_{i}=0$ if the respondent $i$ answers no to the first question.

The double bounded model, proposed by Hanemann (1985) and Carson (1985), consists of asking a second bid (follow-up question) to the respondent. If the respondent $i$ answers yes to the first bid, $b_{1 i}$, the second bid $b_{2 i}$ is higher and lower otherwise. The standard procedure, Hanemann (1985) and Carson (1985), assumes that respondents' WTPs are independent of the bids and deals with the second response in the same manner as the first discrete choice question:

$$
W_{1 i}=W_{0 i} \quad \text { and } \quad W_{2 i}=W_{0 i} .
$$

An individual answers yes to the first bid if $W_{1 i}>b_{1 i}$ and yes to the second bid if $W_{2 i}>b_{2 i}$. Thus, the double bounded model assumes that the same random utility model generates both responses to the first and the second bid.

However, introduction of follow-up questioning can generate inconsistency between answers to the second and first bids. To deal with inconsistency of responses, several models have been proposed in the literature.

\subsection{Anchoring effect}

Herriges and Shogren (1996)'s approach considers a model in which the follow-up question can modify the willingness to pay. According to them, respondents combine their 
prior WTP with the value provided by the first bid, this anchoring effect is then defined as follows

$$
W_{1 i}=W_{0 i} \quad \text { and } \quad W_{2 i}=(1-\gamma) W_{1 i}+\gamma b_{1 i}
$$

where $0 \leq \gamma \leq 1$. An individual answers yes to the first bid if $W_{1 i}>b_{1 i}$ and yes to the second bid if $W_{2 i}>b_{2 i}$. From (4), it follows that,

$$
r_{1 i}=1 \quad \Leftrightarrow \quad W_{0 i}>b_{1 i} \quad \text { and } \quad r_{2 i}=1 \quad \Leftrightarrow \quad W_{2 i}>b_{2 i}
$$

The economic interpretation is rather simple. Individuals are supposed to adjust their initial WTP by doing a weighted average of this WTP with the proposed amount. Thus, $\gamma$ measures the importance of anchoring. It ranges from $\gamma=0$ which means that no anchoring is at work, to $\gamma=1$ which means that subjects ignore their prior WTP and replace it with the proposed bid. This model is thus a simple and efficient manner to test the importance of anchoring. The wider is the anchoring effect, the less information provided by the follow-up question.

\section{A more general model}

This last model assumes that only the follow-up question gives rise to anchoring effects and only the first bid has an influence on the second answer. These two last hypotheses are quite restrictive and we can show that the model is still valid if we consider a more general anchoring effect, that is, both bids can influence subject's responses.

Let us assume that individuals can combine their prior WTP with the values provided by the current and by the past bids offer. It leads us to consider the following model

$$
W_{1 i}=(1-\gamma) W_{0 i}+\gamma b_{1 i} \quad \text { and } \quad W_{2 i}=(1-\delta) W_{1 i}+\delta b_{2 i}
$$

where $0 \leq \gamma \leq 1$ and $0 \leq \delta \leq 1$. An individual answers yes to the first bid offer if:

$$
r_{1 i}=1 \quad \Leftrightarrow \quad W_{1 i}>b_{1 i} \quad \Leftrightarrow \quad(1-\gamma) W_{0 i}+\gamma b_{1 i}>b_{1 i} \quad \Leftrightarrow \quad W_{0 i}>b_{1 i}
$$

This last condition suggests that a potential anchoring effect of the first bid offer does not influence the subject's response to the initial question. An individual answers yes to the second bid offer if:

$$
r_{1 i}=1 \quad \Leftrightarrow \quad W_{2 i}>b_{2 i} \quad \Leftrightarrow \quad(1-\delta) W_{1 i}+\delta b_{2 i}>b_{2 i} \quad \Leftrightarrow \quad W_{1 i}>b_{2 i}
$$

This last condition suggests that a potential anchoring effect of the second bid offer does not influence the subject's response to the follow-up question. Moreover, we can see that the first bid offer can influence the second answer, because $W_{1 i}$ is a combination of the prior WTP and of the value provided by the first bid.

Finally, these results show that the current bid offer can have an impact on the WTP but does not affect the subject's responses. Only the first bid offer can influence the answer to the follow-up question. It follows that the parameter $\delta$ cannot be estimated.

This suggest the remarkable conclusion that when we use the model proposed by Herriges and Shogren (1996) in practice, we can assume a potential anchoring effect of both bids. 


\section{$2.2 \quad$ Shift effect}

Alberini, Kanninen, and Carson (1997) assume that the proposition of two bids may cause individual WTP amount to systematically shift between the two responses. Thus, the two answers are not based on the same WTP and this can explain inconsistency of responses. A shift in WTP is defined as follows:

$$
W_{1 i}=W_{0 i} \quad \text { and } \quad W_{2 i}=W_{1 i}+\delta
$$

where the parameter $\delta$ represents the structural shift.

Such a model is inspired by the following intuition. The first bid may be interpreted as providing information about the cost of the object. Thus, an individual who accept the first bid offer may understand the second bid as a proposition to pay an additional amount for the same object. It follows that this individual may cut down their answers to take that phenomenon into account. Symmetrically, when an individual rejects the first bid offer, the follow-up question could be interpreted as a proposition for a lower quality level of the object. Again, it may lead individual to cut down their answers. In such case, the parameter $\delta$ is expected to be negative.

A positive $\delta$ is however possible and could be interpreted as "yea saying" behavior: an individual overestimate its WTP in order to acknowledge the interviewer's proposition. But, we are not aware of data supporting this interpretation, i.e. estimated values of $\delta$ are negative.

Note that a model with shift effects assumes that only the follow-up question gives rise to shift effect and the shift is independent of the bids proposed. These two last hypothesis are quite restrictive. Indeed, it could be difficult to believe that the respondent answers the first question truthfully, and that the behavioral responses is not the same if the proposed bid is close to the individual's true WTP or if it is far from it. However, these hypotheses are required by an identification condition and we cannot relax them as we have done in the anchoring model.

\subsection{Anchoring and Shift effects}

Whitehead (2002) modifies the Herriges and Shogren anchoring model to allow both anchoring and shift effects,

$$
W_{1 i}=W_{0 i} \quad \text { and } \quad W_{2 i}=(1-\gamma) W_{1 i}+\gamma b_{1 i}+\delta
$$

The interpretation is simply a certain combination of both the anchoring and the shift effect explanations. Indeed, we can rewrite $W_{2 i}=W_{1 i}+\gamma\left(b_{1 i}-W_{1 i}\right)+\delta$, that is, an individual may update its prior WTP with a constant term (shift) and a multiplicative factor of the distance between the prior WTP and the first bid offer (anchoring). See Aadland and Caplan (2004) and Whitehead (2004) for estimation details. 


\subsection{Framing effect}

DeShazo (2002) proposes decomposing iterative questions into their ascending and descending sequences. His empirical results suggest that inconsistency of responses occur only in ascending sequences. It leads him to recommend using in practice the doublebounded model with only decreasing follow-up questions. This last model can be written,

$$
W_{1 i}=W_{0 i} \quad \text { and } \quad W_{2 i}=W_{0 i} \quad \text { if } \quad r_{1 i}=0
$$

The distinction between ascending and descending sequences leads Deshazo to attribute the parameter inconsistency to framing effect rather than anchoring effect. Indeed, using prospect theory (Kahneman and Tversky 1979), he argues that if the first subject's response is "yes", the first bid offer is interpreted as a reference point: compared to it, the follow-up question is framed as a loss and thus, individuals are more likely to answer " no" to the second offer. In contrast, if the first subject's response is "no", the first bid offer is not interpreted as a reference point. Thus, the behavioral responses to ascending versus descending iterative questions are different.

\subsection{New models}

Empirical results based on all the previous models show that in the presence of anchoring effect, shift effect or framing effect, the estimated mean and the estimated dispersion of WTP can be significantly biased. Herriges and Shogren (1996) conclude that the efficiency gains from the follow-up question are lost once we controlled for the anchoring effect. They suggest to use the single-bounded model in the presence of significant anchoring effect and thus, to remove the follow-up questions. DeShazo (2002) shows that most of the biases are more likely to occur in the ascending sequence. It leads him to recommend to keep the follow-up questions from the descending sequences and to remove the follow-up questions from the ascending sequences only.

In order to get information from the ascending sequences back, we propose to correct biases in the follow-up questions from the ascending sequences ${ }^{2}$. We consider three different models, with $W_{1 i}=W_{0 i}$ :

Framing 8 Anchoring effects -

$$
W_{2 i}=W_{1 i}+\gamma\left(b_{1 i}-W_{1 i}\right) r_{1 i}
$$

If the subject's response is " $n o$ " to the first bid offer $r_{1 i}=0$ and $W_{2 i}=W_{1 i}$, otherwise the WTP is updated with an anchoring effect, as defined in the model proposed by Herriges and Shogren (1996).

\footnotetext{
${ }^{2}$ As long as the model (11), proposed by DeShazo (2002), provides consistent results with the singlebounded model, biases occur in ascending sequences only. Thus, there is no need to consider more complicated models where biases occur in both ascending and descending sequences.
} 


$$
W_{2 i}=W_{1 i}+\delta r_{1 i}
$$

If the subject's response is " $n o$ " to the first bid offer $r_{1 i}=0$ and $W_{2 i}=W_{1 i}$, otherwise the WTP is updated with a shift effect, as defined in the model proposed by Alberini, Kanninen, and Carson (1997).

Framing 85 Anchoring 85 Shift effects -

$$
W_{2 i}=W_{1 i}+\gamma\left(b_{1 i}-W_{1 i}\right) r_{1 i}+\delta r_{1 i}
$$

If the subject's response is "no" to the first bid offer $r_{1 i}=0$ and $W_{2 i}=W_{1 i}$, otherwise the WTP is updated with both anchoring and shift effects, as defined in the model proposed by Whitehead (2002). Implementation of this model can be based on a probit model, with the probability that the individual $i$ answers yes to the $j^{\text {th }}$ question, $j=1,2$ equals to:

$$
P\left(W_{j i}>b_{j i}\right)=\Phi\left[X_{i} \alpha-\frac{1}{\sigma} b_{j i}+\theta\left(\left(b_{1 i}-b_{j i}\right) D_{j} r_{1 i}\right)+\lambda\left(D_{j} r_{1 i}\right)\right]
$$

where $D_{1}=0$ and $D_{2}=1, \alpha=\beta / \sigma, \theta=\gamma /(\sigma-\gamma \sigma)$ and $\lambda=\delta /(\sigma-\gamma \sigma)$. Based on this equation, the parameters are interrelated according to:

$$
\beta=\alpha \sigma, \quad \gamma=\theta \sigma /(1+\theta \sigma) \quad \text { and } \quad \delta=\lambda \sigma(1-\gamma) .
$$

The models proposed in (12) and (13) are two special cases of the model proposed in (14), respectively with $\delta=0$ and $\gamma=0$. It follows that, they can be implemented based on the probability (15), respectively with $\lambda=0$ and $\theta=0$.

\section{Application}

To test our model empirically, we use the main results of a contingent valuation survey which was carried out within a research program that the French Ministry in charge of environmental affairs started in 1995. Is is based on a contingent valuation survey which involves a sample of users of the natural reserve of Camargue ${ }^{3}$. The purpose of the contingent valuation survey was to evaluate how much individuals were willing to pay to

\footnotetext{
${ }^{3}$ The Camargue is a wetland in the south of France covering 75000 hectares. The Camargue is a major wetland in France and is host to many fragile ecosystems. The exceptional biological diversity is the result of water and salt in an "amphibious" area inhabited by numerous species. The Camargue is the result of an endless struggle between the river, the sea and man. During the last century, while the construction of dikes and embankments salvaged more land for farming to meet economic needs, it cut off the Camargue region from its environment, depriving it of regular supplies of fresh water and silt previously provided by flooding. Because of this problem and to preserve the wildlife, the water resources are now managed strictly. There are pumping, irrigation and draining stations and a dense network of channels throughout the river delta. However, the costs of such installations are quite large.
} 


\begin{tabular}{|c|c|c|c|c|c|}
\hline Model & $\mu$ & $\sigma$ & $\gamma$ & $\delta$ & $\ell$ \\
\hline Single & $\begin{array}{ll}113.52 & {[87.9 ; 138.7]}\end{array}$ & 45.38 (23.61) & - & 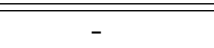 & -53.3 \\
\hline Double & $81.78 \quad[78.2 ; 85.5]$ & 42.74 (5.23) & - & - & -179.6 \\
\hline Anchoring & $\begin{array}{ll}126.38 & {[98.2 ; 155.4]}\end{array}$ & 82.11 (40.83) & $0.52(0.23)$ & - & -176.7 \\
\hline Shift & $89.69 \quad[85.6 ; 93.8]$ & $44.74 \quad(5.77)$ & - & $-8.10 \quad(2.90)$ & -175.3 \\
\hline Anchoring $\mathscr{E}$ Shift & 141.38 [107.3;176.0] & 85.50 (43.78) & 0.52 (0.24) & $-7.81 \quad$ (2.91) & -172.8 \\
\hline Framing & $106.72 \quad[90.9 ; 121.8]$ & 40.39 (11.91) & - & - & -68.8 \\
\hline Fram E Anch & "106.71 [93.6;119.3] & 60.19 (14.77) & $0.40(0.16)$ & - & -176.9 \\
\hline Fram \& Shift & 116.98 [103.9;129.7] & $65.03(14.40)$ & - & $-30.67(14.33)$ & -171.8 \\
\hline Fram $\&$ Anch $\&$ Shift & 116.39 [101.4;131.1] & 64.63 (16.34) & $-0.02(0.42)$ & $-31.60(21.77)$ & -171.8 \\
\hline
\end{tabular}

Table 1: Mean and dipersion of WTPs in French Francs

preserve the natural reserve using an entrance fee. The survey was administered to 218 recreational visitors during the spring 1997, using face to face interviews. Recreational Visitors were selected randomly in seven sites all around the natural reserve. The WTP question used in the questionnaire was a dichotomous choice with follow-up ${ }^{4}$. There was a high response rate $(92.6 \%)$. For a complete description of the contingent valuation survey, see Claeys-Mekdade, Geniaux, and Luchini (1999).

Means of the WTPs were estimated using a linear model (McFadden and Leonard 1993). Indeed, Crooker and Herriges (2004) show that the simple linear probit model is often more robust in estimating the mean WTP than others parametric and semiparametric models. Table 1 presents estimated means $\hat{\mu}$ and estimated dispersions $\hat{\sigma}$ of the WTPs for all models, with standard errors given in parentheses. The mean of WTPs is a function of parameters: its standard error and its confidence interval cannot be obtained directly from the estimation results. Confidence intervals of $\hat{\mu}$ are presented in brackets, they are obtained by simulation with the Krinsky and Robb procedure, see Haab and McConnell (2003, pp 106-113) for more details.

From table 1, it is clear that the standard errors (in parentheses) and the confidence intervals (in brackets) decrease considerably when one uses the usual double-bounded model (Double) instead of the single bounded model (Single). This result confirms the expected efficiency gains provided when the second bid is taken into account (Hanemann, Loomis, and Kanninen 1991). However, estimates of the mean of WTPs in both models are very different (113.52 vs. 81.78). Moreover, the mean of WTPs of the single bounded model, $\hat{\mu}=113.52$, does not belong to the $95 \%$ confidence interval of the mean of WTPs in the double bounded model, $[78.2 ; 85.5]$. Such inconsistent results lead us to consider other models, as presented in the previous section.

At first, we estimate a model with anchoring effect (Anchoring), as defined in (4) by Herriges and Shogren (1996). From table 1, we can see that the anchoring parameter, $\hat{\gamma}=0.52$, is significant. Indeed, a Likelihood Ratio test, equals to twice the difference

\footnotetext{
${ }^{4}$ The first bid $b_{1 i}$ was drawn randomly from $\{5,10,15,20,25,30,35,40,45,50,60,70,80,90,100\}$. The second bid $b_{2 i}$ was drawn randomly from the same set of values with $b_{2 i}<b_{1 i}$ and with the additional amount 3 (resp. $b_{2 i}>b_{1 i}$ and 120) if the answer to the first bid was no (resp. yes). The number of answers (no,no), (no,yes), (yes,no) and (yes,yes) are respectively equal to 20,12, 44 and 121.
} 
of the loglikelihood estimates $(\mathrm{LR}=5.78, P$-value $=0.016)$, rejects the null hypothesis $\gamma=0$. This test confirms the presence of an anchoring effect in the respondents' answers. When correcting for anchoring effect, results are consistent, in the sense that, the mean of WTPs of the single bounded model, $\hat{\mu}=113.52$, belongs to the $95 \%$ confidence interval of the anchoring model, $[98.2 ; 155.4]$. However, standard errors and confidence intervals increase significantly, so that, even if follow-up questioning increases precision of parameter estimates (see Double), efficiency gains are completely lost once the anchoring effect is taken into account (see Anchoring). According to this result, "the single-bounded approach may be preferred when the degree of anchoring is substantial" (Herriges and Shogren, 1996, p 124).

Then, we estimate a model with shift effect (Shift), as defined in (9) by Alberini, Kanninen, and Carson (1997). Results lead to similar conclusions than the double bounded model. Indeed, we can see a large gain in efficiency: standard errors and confidence intervals are more precise. Moreover, results are inconsistent: the mean of WTPs of the single bounded model $\hat{\mu}=113.52$ does not belong to the $95 \%$ confidence interval of the shift model, [85.6; 93.8].

Parameter estimates of a model with both anchoring bias and shift effects, as defined in (10) by Whitehead (2002), are given in the line named Anchoring $\&$ Shift. Based on the criterion of maximum likelihood, this model is better than the others $(\hat{\ell}=-172.82)$. Results are consistent, in the sense that, $\hat{\mu}=113.52$ belongs to the $95 \%$ confidence interval of the model with anchoring and shift effects [107.3; 176.0]. However, we can see a loss of precision compared to the single bounded model.

The only one model, previously presented in the literature, which give consistent results with the single bounded model and a gain in efficiency is the model proposed by DeShazo (2002), as defined in (11). Results are presented in the line named Framing. The $95 \%$ confidence interval $[90.9 ; 121.8]$ includes the mean of WTPs $\hat{\mu}=113.52$ and is narrower than the $95 \%$ confidence interval of the single bounded model $[87.9 ; 138.7]$. In his conclusion, Deshazo recommends to remove all the answers which could be influenced by framing effect, that is, the answers to the second bids if the respondents answer yes to the first bids.

From the previous results, it is clear that there is no way to handle the problem of starting point bias in an effective manner. This suggests that the best we can do in practice is to remove the answers which could be subject to starting point bias. Nevertheless, the use of iterative questions should provide more information about the distribution of WTPs. Then, better results should be expected if all the answers to iterative questions are used and if a correct model of starting-point bias is used. To go further, we consider the three new models proposed in the last section, which consider all the answers to the second bids:

- Line Fram $\&$ Anch presents estimation results of the model defined in (12), that is, a model with an anchoring bias in the ascending sequence only. We can see that the $95 \%$ confidence interval of the mean of WTPs is equal to $[93.6 ; 119.3]$. 


\begin{tabular}{|c|c|c|c|c|c|c|c|c|}
\hline Variables & \multicolumn{2}{|c|}{ Single } & \multicolumn{3}{|c|}{ Framing } & \multicolumn{3}{|c|}{ Fram \& Shift } \\
\hline $\bar{\beta}_{0}:$ Constant & 35.43 & $(57.27)$ & & 39.15 & $(47.90)$ & & 80.46 & (49.51) \\
\hline$\beta_{1}:$ Distance home-site & 9.30 & $(5.30)$ & $\star$ & 8.93 & $(3.95)$ & $\star$ & 5.44 & (2.54) \\
\hline$\beta_{2}$ : Using a car to come in & -61.71 & (41.08) & & -59.54 & (31.37) & 夫 & -60.90 & $(28.45)$ \\
\hline$\beta_{3}:$ Employee & 95.86 & $(46.86)$ & 夫 & 88.13 & $(36.99)$ & $\star$ & 69.68 & $(30.04)$ \\
\hline$\beta_{4}:$ Middle class & 109.96 & $(63.60)$ & * & 94.14 & $(46.06)$ & 夫 & 82.69 & $(32.26)$ \\
\hline$\beta_{5}:$ Inactive & 52.58 & $(38.44)$ & & 43.53 & $(32.39)$ & & 50.41 & $(31.37)$ \\
\hline$\beta_{6}:$ Working class & 97.28 & $(68.29)$ & & 91.55 & $(64.34)$ & & 64.69 & $(53.86)$ \\
\hline$\beta_{7}:$ White collars & 80.33 & $(42.16)$ & $\star$ & 68.42 & (32.11) & $\star$ & 65.56 & (26.39) \\
\hline$\beta_{8}:$ Visiting with family & 4.71 & (29.61) & & 3.02 & $(25.60)$ & & 10.51 & (25.23) \\
\hline$\beta_{9}:$ Visiting alone & 61.11 & $(101.67)$ & & 53.61 & (81.13) & & 97.05 & $(58.27)$ \\
\hline$\beta_{10}$ : Visiting with a group & 44.79 & $(47.90)$ & & 51.05 & $(49.65)$ & & 4.56 & $(36.07)$ \\
\hline$\beta_{11}:$ First Visit & 51.42 & (35.29) & & 41.57 & (29.01) & & 14.37 & $(17.47)$ \\
\hline$\beta_{12}:$ New facilities proposed & 56.93 & (32.12) & * & 55.78 & (22.83) & $\star$ & 43.59 & $(16.72)$ \\
\hline$\beta_{13}$ : Other financing proposed & -32.03 & $(27.60)$ & & -30.04 & $(18.19)$ & & -22.85 & $(14.59)$ \\
\hline$\beta_{14}:$ South-West & -24.18 & $(33.57)$ & & -21.19 & (26.83) & & -33.04 & $(28.36)$ \\
\hline$\beta_{15}:$ South-East & 42.04 & $(58.26)$ & & 40.94 & $(44.80)$ & & 38.69 & $(37.50)$ \\
\hline$\beta_{16}:$ Questionnaire type & -28.19 & (23.34) & & -28.19 & (18.63) & & -13.21 & $(13.50)$ \\
\hline$\beta_{17}:$ Investigator 1 & 23.44 & $(56.29)$ & & 23.43 & $(45.05)$ & & 8.43 & $(38.95)$ \\
\hline$\beta_{18}$ : Investigator 2 & -17.12 & $(57.52)$ & & -11.22 & $(46.35)$ & & -27.90 & $(42.07)$ \\
\hline$\sigma$ & 45.38 & (23.61) & 夫 & 40.39 & $(11.91)$ & 夫 & 65.03 & $(14.40)$ \\
\hline$\delta$ & - & & & - & & $\star$ & -30.67 & $(14.33)$ \\
\hline
\end{tabular}

Table 2: Parameter estimates, standard errors in parentheses $(\star$ : significant at $95 \%)$

- Line Fram $\&$ Shift presents estimation results of the model defined (13), that is, a model with a shift effect in the ascending sequence only. We can see that the $95 \%$ confidence interval of the mean of WTPs is equal to $[103.9 ; 129.7]$.

- Line Fram $\mathscr{E}$ Anch $\mathscr{E}$ Shift presents estimation results of the model defined in (14), that is, a model with an anchoring bias and a shift effect in the ascending sequence only. We can see that the $95 \%$ confidence interval of the mean of WTPs is equal to $[101.4 ; 131.1]$.

It is clear that for these three models, results are consistent with the single bounded model: the mean of WTPs $\hat{\mu}=113.52$ belongs to the three confidence intervals. Furthermore, results are more precise: the standard errors (in parentheses) are smaller and the confidence intervals (in brackets) are narrower than those of the single-bounded model.

In addition, we can remark that the two models Fram $\&$ Anch and Fram 83 Shift are special cases of the model Fram $\mathscr{E}$ Anch $\mathscr{G}$ Shift, respectively with $\delta=0$ and $\gamma=0$. From this last more general model, we cannot reject $\gamma=0(\mathrm{LR}=0.004, P$-value $=0.99)$, but we can reject $\delta=0(\mathrm{LR}=10.31, P$-value $=0.001)$. These results lead us to select the model Fram 8 Shift as the one which fit better our contingent valuation data, that is, a model with shift effect in the ascending sequences only.

Table 2 presents full econometric results of several models with consistent results: the single-bounded model (Single), the model of Deshazo (Framing) and our selected model (Fram $\&$ Shift). The estimates of the vector of coefficients $\beta$ (rather than $\beta / \sigma$ ), the 
standard deviation $\sigma$ and the shift parameter $\delta$ are directly presented, see equations (1), (11) and (13). It is clear from this table that the standard errors in the Fram $\&$ Shift model are nearly always significantly reduced compared to the standard errors in the other models. Indeed, only one parameter is significant in the Single model when eight parameters are significant in the Fram $\& 5$ Shift model. In other words, efficiency gains are still present in our selected model (which take into account all the answers) compared to the other models (which remove answers that could be influenced by the first bid offer).

\section{Conclusion}

Follow-up questions in double bounded model are expected to give more information on the willingness-to-pay of respondents. Then, many economists have favored this last model to obtain gains in efficiency over the single bounded model. However, recent studies show that this model can be inadequate and can give inconsistent results. Many different models have been considered in the literature to correct anomalies in respondent behavior that appear in dichotomous choice contingent valuation data. However, the corrections proposed by these models show that efficiency gains given by the iterative questions are lost when inconsistency of responses is controlled.

The main contribution of this paper is to propose a model to control for startingpoint bias in double bounded model, and, contrary to previous research, still have gains in efficiency relative to a single dichotomous choice question. DeShazo (2002) shows that descending and ascending sequences have different behavioral responses and recommend to restrict the follow-up questions only if the answers to the first bids are no. To benefit from more information, rather than not taking into account the answers which could be influenced by the first bid offer, we propose different models of starting-point bias in ascending iterative questions only. Our empirical results show that a model with shift effects in the ascending questions gives consistent results with the single bounded model and provides large efficiency gains. This support the idea that framing, anchoring and shift effects can be combined in an efficient manner.

\section{References}

Aadland, D. and A. J. Caplan (2004). "Incentive incompatibility and starting-point bias in iterative valuation questions: comment". Land Economics 80(2), 312-315.

Alberini, A., B. Kanninen, and R. Carson (1997). Modeling response incentive effects in dichotomous choice valuation data. Land Economics 73(3), 309-324.

Arrow, K., R. Solow, P. R. Portney, E. E. Leamer, R. Radner, and H. Schuman (1993, January). Report of the NOAA panel on contingent valuation. Technical Report 58(10), p1601-1614.

Bateman, I. and K. Willis (1999). Valuing Environmental Preferences: Theory and Practice of the Contingent Valuation Method in the US, EU, and Developing Countries. 


\section{Oxford University Press.}

Cameron, T. and J. Quiggin (1994). "Estimation using contingent valuation data from a dichotomous choice with follow-up questionnaire". Journal of Environmental Economics and Management 27, p218-234.

Carson, R. (1985). Three essays on contingent valuation. Ph. D. thesis, University of California, Berkeley.

Claeys-Mekdade, C., G. Geniaux, and S. Luchini (1999). Quelle valeur attribuer à la camargue? une perspective interdisciplinaire économie et sociologie. In P. Point (Ed.), La valeur économique des hydrosystèmes. Méthodes et modèles d'évaluation des services délivrés, Chapter 7, pp. 137-168. Paris: Economica.

Crooker, J. R. and J. A. Herriges (2004). "Parametric and semi-nonparametric estimation of willingness-to-pay in the dichotomous choice contingent valuation framework". Environmental and Resource Economics 27, 451-480.

DeShazo, J. R. (2002). "Designing transactions without framing effects in iterative question formats". Journal of Environmental Economics and Management 43, p360-385.

Haab, T. C. and K. E. McConnell (2003). Valuing Environmental and Natural Resources. Edwar Elgar.

Hanemann, W. (1985). "Some issues in continuous and discrete response contingent valuation studies". Northeast Journal of Agricultural Economics 14, 5-13.

Hanemann, W., J. Loomis, and B. Kanninen (1991). "Statistical efficiency of doublebounded dichotomous choice contingent valuation". American Journal of Agricultural Economics 73, 1255-1263.

Hausman, J. (1993). Contingent valuation : A critical assessment. North-Holland.

Herriges, J. A. and J. F. Shogren (1996). "Starting point bias in dichotomous choice valuation with follow-up questioning". Journal of Environmental Economics and Management 30, 112-131.

Kahneman, D. (1992). "Reference points, anchor norms, and mixed feelings". Organizational Behavior and human Decision Processes 51, 296-312.

Kahneman, D. and A. Tversky (1979). "Prospect theory: an analysis of decisions under risk". Econometrica 47, 313-327.

McFadden, D. and G. Leonard (1993). Issues in the contingent valuation of environmental goods: Methodologies for data collection and analysis. In Contingent Valuation: a critical Assessment, pp. 165-215. New York: North-Holland: Hausman.

Mitchell, R. C. and R. T. Carson (1989). Using Surveys to Value Public Goods : The contingent Valuation Method. Washington D.C.: Resources for the Future.

Whitehead, J. C. (2002). "Incentive incompatibility and starting-point bias in iterative valuation questions". Land Economics 78, p285-297.

Whitehead, J. C. (2004). "Incentive incompatibility and starting-point bias in iterative valuation questions: reply". Land Economics 80(2), 316-319. 